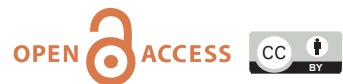

doi: $10.31729 /$ jnma.5091

\title{
Epidemiology of Femur Fractures in Children: A Descriptive Cross Sectional Study Based on a Rural Population of Nepal
}

\author{
Poojan Kumar Rokaya, ${ }^{1}$ Dhan Bahadur Karki, ${ }^{1}$ Mangal Rawal,, Deoman Limbu, 'Bishnu Dutta Acharya, ${ }^{1}$ Pratap \\ Babu Bhandari ${ }^{2}$ \\ 'Department of Orthopedics \& Trauma Surgery, Karnali Academy of Health Sciences, Jumla, Karnali, Nepal, \\ ${ }^{2}$ Department of Orthopedics, Chitwan Medical College, Chitwan, Nepal.
}

\begin{abstract}
Introduction: Femur fracture in children is one of the most common lower limb fractures which require inpatient care. The aim of this study is to determine the epidemiology of femoral shaft fractures in children from a rural population of Karnali Nepal.

Methods: Hospital records were retrospectively reviewed from May 2017 to April 2020 to identify all the children with femur fracture. Sociodemographic profile, mode of injury, fracture pattern and location, time of presentation, initial treatment by traditional bone setters, treatment method and duration of hospital stay were noted. Data analysis was done using Statistical Package for Social Sciences version 20 .
\end{abstract}

Results: Altogether 104 children were identified. The mean age was 5.55 years and boys predominated $65(62.5 \%)$. Falls were the major mode of injury in $65(62.4 \%)$ patients. Fractures were frequently noted between April 15 to August 15. There were four (3.8\%) open fractures and concurrent fracture observed in eight $(7.6 \%)$ patients. Ten $(9.6 \%)$ children received prior treatment from traditional bonesetters. Treatment methods included hip spica 62 (59.6\%), elastic intramedullary nailing 30 $(28.8 \%)$ and plate fixation $12(11.5 \%)$. The duration of hospital stay in the nailing and plate fixation group was 11.43 days and 18 days respectively

Conclusions: Fracture was common in 2-6 years of age group in boys during summer. Fall from cliff, rooftop and ladder were the major preventable cause of fracture. Delayed presentation and prior treatment with traditional bone setters add special challenges to orthopedic surgeons working in rural teaching hospital.

Keywords: children; epidemiology; femur; fracture; rural.

\section{INTRODUCTION}

Femoral shaft fracture in children is one of the most common lower limb fractures requiring inpatient admission. They represent $1.6 \%$ of all fractures in children. ${ }^{1}$ At present, we treat children below six years with one and a half spica with or without prior traction. For children above six years treatment depends upon child's age, body habitus, fracture personality and location, concurrent injuries, skin condition and socioeconomic factors. Available options include elastic intramedullary nailing (EIN), external fixation and

Correspondence: Dr. Poojan Kumar Rokaya, Department of Orthopedics \& Trauma Surgery, Karnali Academy of Health Sciences, Jumla, Karnali, Nepal. Email: pkr2039@gmail.com, Phone:+977-9849083461. 
osteosynthesis with dynamic compression plate and screws.

Various studies on cause, pattern and treatment methods of childhood femur fractures have been conducted in urban settings of developed countries. ${ }^{2-}$ ${ }^{5}$ To our understanding, epidemiological study on childhood femur fracture has not been conducted in rural population of Nepal till date. Our teaching hospital is situated in himalayan mountainous district Jumla of Karnali province. It is the health referral center of adjoining four districts Kalikot, Mugu, Dolpa and Humla which extends from 2500 to 4000 meters in elevation and inhabits 426,026 people. ${ }^{6} \mathrm{Karnali}$ province is one of the remotest and most deceived regions of Nepal. Karnali has literacy rate of $62.7 \%$ and the lowest human development index 0.445 as compared to other parts of Nepal. ${ }^{7}$

The main objective of this study is to determine the clinical sociodemographic parameters of femoral shaft fractures and to review the treatment methods in children from rural population of Karnali Nepal.

\section{METHODS}

A descriptive cross sectional single centre study was carried out at Karnali Academy of Health sciences Jumla, Nepal after ethical approval from Institutional Review Committee (IRC KAHS Reference; 35/076/077). Hospital inpatient records, operation notes and radiological charts were retrospectively reviewed from May 2017 to April 2020 to identify all children with femoral shaft fractures. Patient sociodemographic profile, mode of injury, fracture pattern and location, concurrent injuries, nerve and vascular injury, time of presentation, initial treatment by traditional bone setters, treatment method and length of hospital stay (LOHS) were recorded in patient proforma. Children from birth to 14 years of age admitted for femoral shaft fracture with complete medical records were included in the study. Exclusion criteria included: children above 14 years, inter trochanter or neck of femur fracture, femur growth plate injury, intra-articular fracture and patient with incomplete clinical details.

Initially children with femoral shaft fracture were kept in Buck's traction with $<2.5 \mathrm{Kg}$ weight. Some children were referred in from others centers with immobilization in above knee posterior plaster slab. Duration of traction was determined by patients age, fracture pattern, initial shortening of more than two $\mathrm{cm}$ and skin condition. Hip spica was applied under appropriate analgesia after fracture reduction by orthopedic surgeons. Spica incorporated the lower abdomen, pelvis, thigh and leg of injured side and thigh of contralateral side with cross bar in between. The optimal position of hip spica included bilateral hip abduction of $30^{\circ}$, hip and knee flexed $30-45^{\circ}$ and leg in $15^{\circ}$ of external rotation. X-Ray of the affected thigh was obtained to assess reduction. Children with spica were discharged the following day. Danger signs of plaster and spica care were advised to the parents. Open fractures were managed with wound debridement, intravenous antibiotics and skeletal traction.

Use of EIN or plate fixation was dependent on patient's age, fracture pattern and location. EIN was performed using a standard technique. Patient was placed in a fracture table and retrograde nailing was done protecting the distal femoral physes. Nail size was calculated from $40 \%$ of narrowest femoral medullary canal. Closed reduction was attempted under fluoroscopic guidance. Mini open reduction with minimal periosteal stripping was done when closed reduction failed upon three to four attempts. Affected extremity was immobilized in above knee posterior plaster slab. Check X-Ray was ordered on the first postoperative day.

Unstable femoral shaft fracture involving the distal or proximal third in patient older than six years were fixated with plate and screw. In supine position through direct lateral approach, fascia lata and vastus lateralis were incised to reach the fracture site. Fracture was reduced using bone clamps and fixated with narrow compression plate and screws. Three to four screws were placed on either side of fracture. Hemostasis achieved, wound closed in layers after irrigation with normal saline. Plaster slab immobilization was not used in this cohort. Patients were advised for gentle range of motion of ankle and knee as pain tolerated. Operative procedure was performed by council registered orthopedic surgeons. All the relevant data were collected and entered in patient proforma. Descriptive analysis of the data was done using Statistical Package for Social Sciences (SPSS Inc. version 20, Chicago, Illinois) to find out the number, percentage, mean, standard deviation, average and range.

\section{RESULTS}

Altogether 104 children were admitted for femoral shaft fractures over a period of 3 years. The geographical distribution of patients is shown (Figure 1). A total of $28(27 \%)$ children were primarily managed in other districts and were referred in cases. 
Rokaya et al. Epidemiology of Femur Fractures in Children: A Descriptive Cross-sectional Study Based on a Rural Population of Nepal

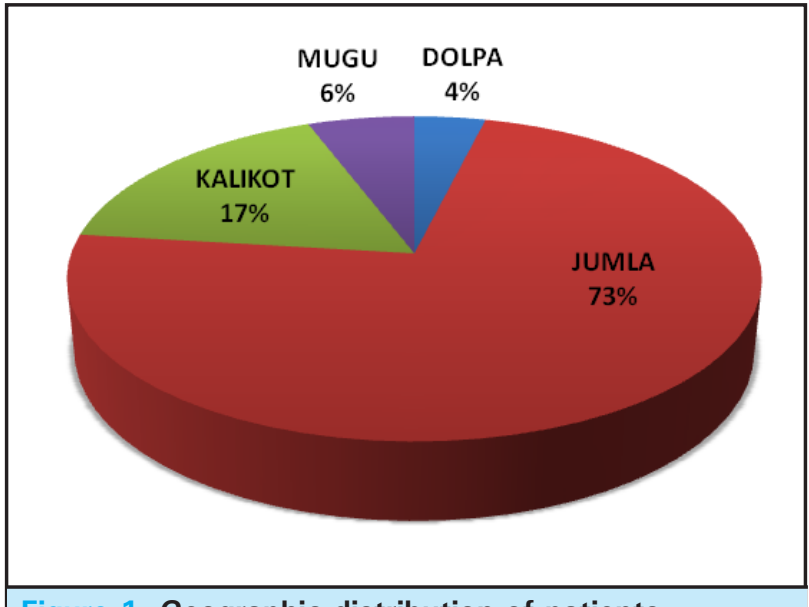

Figure 1. Geographic distribution of patients.

There were $65(62.5 \%)$ boys and $39(37.5 \%)$ girls. The mean age was 5.55 years ( 8 months -14 years). Fracture was prevalent in 2-6 years of age group as mentioned (Figure 2).

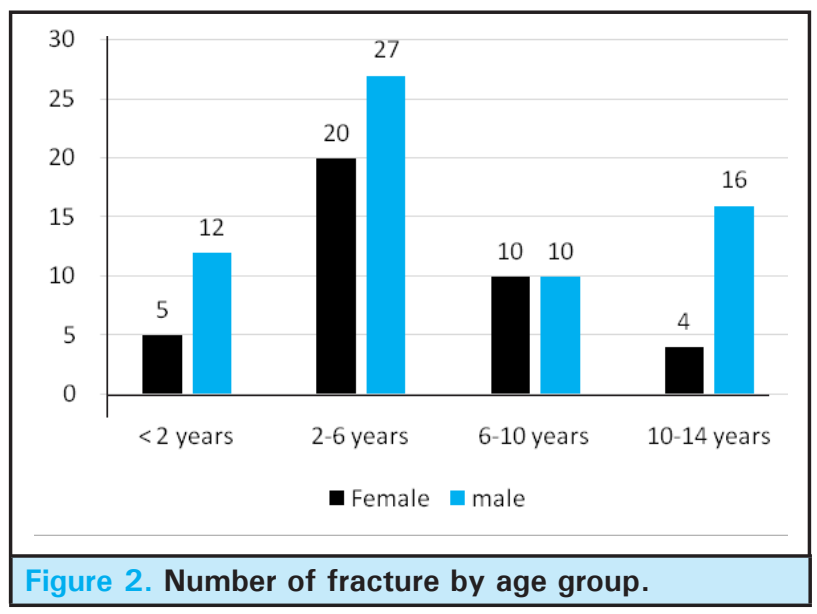

Patient clinical demographic profile is presented (Table 1).

\begin{tabular}{|lll|}
\hline \multicolumn{3}{|l|}{ Table 1. Clinical demographic profile of patient. } \\
\hline \multirow{3}{*}{ Gender } & Variables & $\mathbf{n}(\%)$ \\
& Boys & $65(62.5)$ \\
& Girls & $39(37.5)$ \\
& Right & $46(44.2)$ \\
& Left & $58(55.8)$ \\
& Fall from ladder & $26(25)$ \\
& Fall from rooftop & $23(22.1)$ \\
Mode of & Fall from cliff & $16(15.3)$ \\
injury & Sports & $13(12.5)$ \\
& Road traffic accidents & $10(9.6)$ \\
& Fall from bicycle & $9(8.6)$ \\
& Physical assault & $4(3.8)$ \\
& Fall from horse & $3(2.8)$ \\
\hline
\end{tabular}

\begin{tabular}{|lll|}
\hline \multirow{2}{*}{$\begin{array}{l}\text { Fracture type } \\
\text { fractures }\end{array}$} & $\begin{array}{l}\text { Open } \\
\text { Close }\end{array}$ & 100 (9.8) \\
& Mild head injury & \\
& Ipsilateral distal radius & \\
& physeal injury & $3(2.8)$ \\
& Pubic Rami fracture & $1(0.9)$ \\
& Ipsilateral Ring and little & $1(0.9)$ \\
& finger phalanx fracture & $1(0.9)$ \\
& Contralateral Iliac Blade & $1(0.9)$ \\
& fracture & $1(0.9)$ \\
& Contralateral hemithorax & \\
& $6-8$ rib fracture & \\
\hline
\end{tabular}

The seasonal pattern of fracture is shown (Figure 3 ). Right extremity was involved in 46 (44.2\%) and left extremity in 58 (55.8\%). Fall from cliff, ladders and rooftops were the major mode of injury accounting for $65(62.4 \%)$ falls. Fracture pattern and location are summarized (Table 2).

\begin{tabular}{|lll|}
\hline \multicolumn{3}{|l|}{ Table 2. Fracture pattern and location. } \\
\hline \multirow{7}{*}{ Fracture Pattern } & $\mathrm{n}(\%)$ \\
& Transverse & $37(35.5)$ \\
& Short oblique & $16(15.3$ \\
& Long oblique & $13(12.5$ \\
& Spiral & $22(21.1)$ \\
& Comminuted & $10(9.6)$ \\
& Undisplaced & $6(5.7)$ \\
& Procture Locational Third & $19(18.2)$ \\
& Middle Third & $68(65.3)$ \\
& Distal Third & $17(16.3)$ \\
\hline
\end{tabular}

There were 100 (96.1\%) closed fractures and four $(3.8 \%)$ open fractures. Concurrent fracture was noted in eight $(7.6 \%)$ patients. Ten out of 104 (9.6\%) children were initially managed by traditional bonesetters and faith healers.

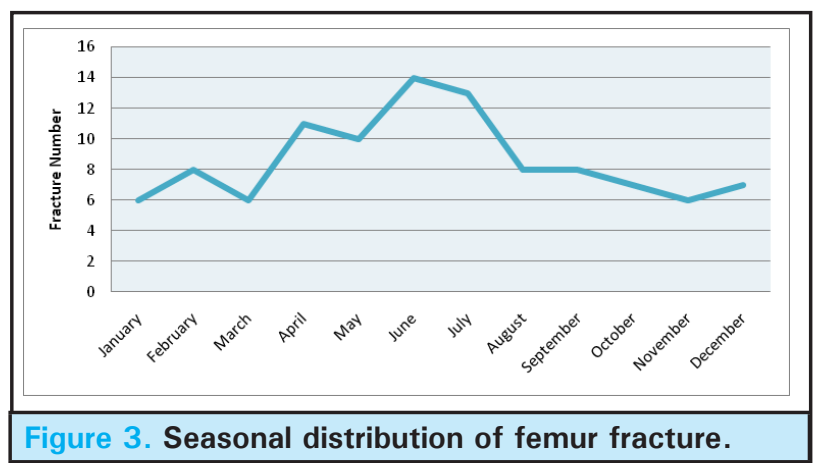

Average duration between day of injury and day of presentation to hospital was 3.11 days (Range 1-8 days). Treatment method with average LOHS is 
Rokaya et al. Epidemiology of Femur Fractures in Children: A Descriptive Cross-sectional Study Based on a Rural Population of Nepal

tabulated (Table 3). We did not notice bilateral fracture, neurovascular injury and mortality related to femur fracture.

\begin{tabular}{|lll|}
\hline \multicolumn{3}{|l|}{ Table 3. Treatment method with LOHS. } \\
\hline & $\mathbf{n}(\%)$ & $\begin{array}{l}\text { LOHS days } \\
\text { Mean } \pm \text { S.D.(Range) }\end{array}$ \\
Hip spica & $62(59.6)$ & $7.52 \pm 4.37(2-16)$ \\
EIN & $30(28.8)$ & $11.43 \pm 4.74(5-19)$ \\
Plate fixation & $12(11.5)$ & $18 \pm 3.33(11-22)$ \\
\hline
\end{tabular}

\section{DISCUSSION}

This study reflects the epidemiological pattern of childhood femoral shaft fracture treated in a rural teaching hospital of Karnali Nepal. The mean age of patient was 5.55 years with common occurrence in 2-6 years of age group. Our finding with respect to age distribution is in contrast to the study conducted by Hinton et al. where they observed bimodal age distribution. ${ }^{8}$ Male outnumbered female with 1.6:1 male to female ratio which is comparable with study conducted by Bridgman et al. ${ }^{9}$ Boys are more commonly involved in risk talking outdoor activities and sports as compared to girls which could relate this gender discrepancy. Fracture was common in summer and spring from April 15 to August 15. Outdoor activities and sports events are more likely in the warm months. Some studies have cited seasonal variation in fracture pattern as a result of increased activities in summer due to school vacation. ${ }^{4-5}$ Fall from ladder, rooftop and cliff were the frequent cause of injury observed in this study accounting for $65(62.4 \%)$ of total falls. This finding differs with epidemiological studies from developed countries with larger series where fall from less than two meters was the predominant cause of injury. ${ }^{3,10}$ Children occasionally climb cliff to cut grass for household purpose in highland of Jumla, Kalikot, Mugu and Humla. People have compulsion to walk in the uneven trails of hills and mountain for their day to day agricultural livelihood. In addition, rooftops are usually open and lack protective bars or railings in most of the rural community of Karnali Nepal. Eight children (7.6\%) with femoral shaft fracture had multiple injuries. Associated injuries in pediatric femoral shaft fracture have been reported up to $8.1 \%$ in the literature. ${ }^{10}$ Multiple injuries in a child with femoral shaft fracture tend to prolong the hospital stay and influence the existing treatment methods. ${ }^{11} \mathrm{We}$ found $100(96.1 \%)$ closed and $4(3.8 \%)$ open femoral shaft fracture. A similar rate of open femur fracture is mentioned in other epidemiological studies. ${ }^{10,11}$ Majority of the fractures $68(65.3 \%)$ were located in the middle third whereas $36(34.5 \%)$ of the fractures were located in the proximal and distal third of femoral shaft. This is in accordance with other studies which revealed similar location of fracture. ${ }^{12,13}$ Average duration between time of injury and time of presentation to hospital was 3.11 days. Delay in presentation is a common scenario in remote health facilities of Karnali because of lack of road access, uneven geographical topography and initial management by traditional bonesetter and faith healers. Absence of road connectivity to all the remote village and shortage of ambulance compels patients to be carried in bamboo basket or stretcher for several days to reach the hospital. In this study, 10 (9.6\%) out of 104 patient received prior treatment with traditional bonesetters and faith healers. Lack of awareness, poverty, negligence by the parents to seek medical advice and unavailability of nearby health facility could have promoted faith healers and traditional bone setters in rural areas of lower middle income country like Nepal. ${ }^{14}$

Our hospital treatment protocol for childhood femoral shaft fracture is individualized on age, body habitus, fracture stability and location, skin condition and associated injures. Among 104 children, 62 (59.6\%) were treated with one and a half hip spica. Hip spica is an accepted treatment method for closed isolated femur fracture in children less than six years. Our treatment method of hip spica with respect to age less than six years is supported by various studies which have advocated immediate to early hip spica for the treatment femoral shaft fractures in children. ${ }^{15-17}$ Till date we are applying one and a half hip spica and have no experience with single leg walking hip spica. Few authors have found single leg walking hip spica to be superior and effective compared to traditional spica casting. ${ }^{18,19}$

Thirty children were managed with EIN. We use EIN for central 2/3 diaphyseal fracture, length stable fracture (transverse, short oblique) in children older than six years for internal fixation of femur fracture. Our current practice is compatible with systemic review and metaanalysis of 1012 patients conducted by Imam et al. who preferred EIN for the treatment of femur fracture in children aged less than 16 years. ${ }^{20}$ Although EIN is ideal for length stable fracture they have been equally effective in length unstable femoral shaft fracture in children less than 11 years. ${ }^{21,22}$

Osteosynthesis with dynamic compression plate and screws was used to treat $12(11.5 \%)$ femoral shaft fractures. Plating is usually preferred in older children with unstable femoral fracture at the proximal and distal third where nailing can be technically difficult. ${ }^{23}$ Plating can achieve excellent stability but at the cost of bleeding, infection and scarring. Plating was done in the conventional manner as per the operating surgeons experience and preference. Minimal invasive submuscular plating has become a viable option for the treatment of length unstable femoral fracture in older 
and obese children. ${ }^{24}$

There has been a decreasing trend in duration of hospital stay in pediatric femur fracture managed operatively in the developed countries where they have standard and accessible health facility. The duration of hospital stay in the EIN and plate fixation group was 11.43 days and 18 days respectively which is contradictory to the western literature. ${ }^{25,26}$ Patient reside in the remote parts where they may not have health facility to remove the sutures during postoperative period. Parent's willingness to get their child discharged after suture removal usually on 12 to 14 postoperative days lengthens the hospital stay in our setup.

Retrospective nature of the study with small sample size is one of the limitations of this study. We could not comment on fracture union, complications and outcome as this study was intended to focus on epidemiological parameters of fracture. Study was conducted on patients presenting to one of the rural health referral center of Nepal which does not represent all children of Nepal. Multi centric study should be conducted in other rural health care centers to consolidate our results.

Based on our findings various activities to consider with priorities are 1) improve structural design of rooftops and ladders in rural areas 2) promote research on preventable injuries 3) campaign for awareness in the rural community regarding preventable injuries 4) counsel faith healers and traditional bone setters on their perception towards injured patients 5) strengthen the existing health referral system 6) access to specialized health service in rural parts of country.

\section{CONCLUSIONS}

Femur fracture was common in 2-6 years of age in boys during summer. Fall from cliff, rooftop and ladder were the major preventable cause of fracture. Delay in presentation and initial treatment by traditional bone setters add special challenges to orthopedic surgeon working in rural teaching hospital.

\section{ACKNOWLEDGEMENTS}

We would like to appreciate Dr. Seshananda Sanjel and Mr. Prem Prasad Panta for their help and support in data analysis.

\section{Conflict of Interest: None.}

\section{REFERENCES}

1. Tisherman RT, Hoellwarth JS, Mendelson SA. Systematic review of spica casting for the treatment of paediatric diaphyseal femur fractures. J Child Orthop. 2018;12(2):136-144. [PubMed]

2. Hedlund $R$, Lindgren $U$. The incidence of femoral shaft fractures in children and adolescents. J Pediatr Orthop. 1986;6(1):47-50. [PubMed]

3. Talbot C, Davis N, Majid I, Young M, Bouamra O, Lecky FE, Jones $\mathrm{S}$. Fractures of the femoral shaft in children: national epidemiology and treatment trends in England following activation of major trauma networks. Bone Joint J. 2018;100-B(1):109-18. [PubMed]

4. Nafei A, Teichert G, Mikkelsen SS, Hvid I. Femoral shaft fractures in children: an epidemiological study in a Danish urban population, 1977-86. J Pediatr Orthop. 1992;12(4):499-502. [PubMed]

5. Miettinen $\mathrm{H}$, Mäkelä EA, Vainio J. The incidence and causative factors responsible for femoral shaft fractures in children. Ann Chir Gynaecol. 1991;80(4):392-5. [ubled]

6. Central Bureau of Statistics. Population and Housing Census;2011. Available from: https://unstats.un.org/ unsd/demographic-social/census/documents/Nepal/ Nepal-Census-2011-Vol1.pdf. [Full Text]

7. Government of Nepal, UNDP. Nepal Human Development Report. 2014. Available from: http://www.hdr.undp.org/ sites/default/files/nepal_nhdr_2014-final.pdf. [Full Text]
8. Hinton RY, Lincoln A, Crockett MM, Sponseller P, Smith G. Fractures of the femoral shaft in children. Incidence, mechanisms, and sociodemographic risk factors. J Bone Joint Surg Am. 1999;81(4):500-9. [PubMed]

9. Bridgman S, Wilson R. Epidemiology of femoral fractures in children in the West Midlands region of England 1991 to 2001. J Bone Joint Surg Br. 2004;86(8):1152-7. [PubMed]

10. Heideken Jv, Svensson T, Blomqvist $P$, Haglund-Åkerlind $Y$, Janarv PM. Incidence and trends in femur shaft fractures in Swedish children between 1987 and 2005. J Pediatr Orthop. 2011;31(5):512-9. [PubMed]

11. Loder RT, O'Donnell PW, Feinberg JR. Epidemiology and mechanisms of femur fractures in children. J Pediatr Orthop. 2006;26(5):561-6. [PubMed]

12. Kirby RM, Winquist RA, Hansen ST Jr. Femoral shaft fractures in adolescents: a comparison between traction plus cast treatment and closed intramedullary nailing. J Pediatr Orthop. 1981;1(2):193-7. [uuMed]

13. Timmerman LA, Rab GT. Intramedullary nailing of femoral shaft fractures in adolescents. J Orthop Trauma. 1993;7(4):331-7. [PubMed]

14. Nwachukwu BU, Okwesili IC, Harris MB, Katz JN. Traditional bonesetters and contemporary orthopaedic fracture care in a developing nation: historical aspects, contemporary status and future directions. Open Orthop J. 2011;5:20-6. [PubMed] 
Rokaya et al. Epidemiology of Femur Fractures in Children: A Descriptive Cross-sectional Study Based on a Rural Population of Nepal

15. Illgen $\mathrm{R}$ 2nd, Rodgers WB, Hresko MT, Waters PM, Zurakowski D, Kasser JR. Femur fractures in children: treatment with early sitting spica casting. J Pediatr Orthop. 1998;18(4):481-7. [PubMed]

16. Mansour AA 3rd, Wilmoth JC, Mansour AS, Lovejoy SA, Mencio GA, Martus JE. Immediate spica casting of pediatric femoral fractures in the operating room versus the emergency department: comparison of reduction, complications, and hospital charges. J Pediatr Orthop. 2010;30(8):813-7. [PubMed]

17. Jauquier N, Doerfler M, Haecker FM, Hasler C, Zambelli PY, Lutz N. Immediate hip spica is as effective as, but more efficient than, flexible intramedullary nailing for femoral shaft fractures in pre-school children. J Child Orthop. 2010;4(5):461-5. [․ubMed]

18. Leu D, Sargent MC, Ain MC, Leet AI, Tis JE, Sponseller PD. Spica casting for pediatric femoral fractures: a prospective, randomized controlled study of single-leg versus double-leg spica casts. J Bone Joint Surg Am. 2012;94(14):1259-1264. [PubMed]

19. Flynn JM, Garner MR, Jones KJ, D'Italia J, Davidson RS, Ganley TJ, Horn BD, Spiegel D, Wells L. The treatment of low-energy femoral shaft fractures: a prospective study comparing the "walking spica" with the traditional spica cast. J Bone Joint Surg Am. 2011 Dec 7;93(23):2196-202. [PubMed]

20. Imam MA, Negida AS, Elgebaly A, et al. Titanium Elastic Nails Versus Spica Cast in Pediatric Femoral Shaft Fractures: A Systematic Review and Meta-analysis of 1012 Patients. Arch Bone Jt Surg. 2018;6(3):176-188. [PubMed]
21. Siddiqui AA, Abousamra O, Compton E, Meisel E, Illingworth KD. Titanium Elastic Nails are a Safe and Effective Treatment for Length Unstable Pediatric Femur Fractures. J Pediatr Orthop. 2020 Aug;40(7):e560-e565. [PubMed | DOI]

22. Allen JD, Murr K, Albitar F, Jacobs C, Moghadamian ES, Muchow R. Titanium Elastic Nailing has Superior Value to Plate Fixation of Midshaft Femur Fractures in Children 5 to 11 Years. J Pediatr Orthop. 2018;38(3):e111-e117. [PubMed]

23. Abdelgawad AA, Sieg RN, Laughlin MD, Shunia J, Kanlic EM. Submuscular bridge plating for complex pediatric femur fractures is reliable. Clin Orthop Relat Res. 2013;471(9):2797-807. [PubMed]

24. $\mathrm{Li} Y$, Hedequist DJ. Submuscular plating of pediatric femur fracture. J Am Acad Orthop Surg. 2012;20(9):596-603. [PubMed]

25. Flynn JM, Luedtke LM, Ganley TJ, Dawson J, Davidson RS, Dormans JP, Ecker ML, Gregg JR, Horn BD, Drummond DS. Comparison of titanium elastic nails with traction and a spica cast to treat femoral fractures in children. J Bone Joint Surg Am. 2004;86(4):770-7. [PubMed]

26. Shemshaki HR, Mousavi H, Salehi G, Eshaghi MA. Titanium elastic nailing versus hip spica cast in treatment of femoral-shaft fractures in children. J Orthop Traumatol. 2011;12(1):45-8. [PubMed] 